\title{
Work-home interaction and psychological distress during the COVID-19 pandemic: The mediation effect of cyberloafing
}

\author{
Sari Novianti, Bertina Sjabadhyni \\ Faculty of Psychology, University of Indonesia, Indonesia \\ Corresponding author: sarinovianti@gmail.com
}

\section{ARTICLE INFO}

\section{Article history}

Received November 20, 2020

Revised June 6, 2020

Accepted June 18, 2020

Keywords

COVID-19;

cyberloafing;

psychological distress;

work from home;

work-home interaction.

\begin{abstract}
Work from home is one of the policies chosen by the government due to the COVID -19 pandemic; however, work-home interactions (WHIs) can place a burden on one domain. This study aimed to examine the relationship between the dimensions of WHIs and psychological distress and how cyberloafing mediates this relationship. Data were collected with an online survey tool from 2,349 participants who worked at a government institution in Indonesia with employees across the country to test the proposed hypothesis. The results show that all forms of WHIs cause psychological distress. Further, a high level of negative work-home interactions (NWHIs) and negative home-work interactions (NHWIs) increase psychological distress. Conversely, a high level of positive work-home interactions (PWHIs) and positive home-work interactions (PHWIs) reduce psychological distress. In addition, this study's results also show that cyberloafing mediates the relationships between NWHIs, NHWIs, PWHIs, and psychological distress. This study implies the organization need to provide mental support and technology support to ensure the work of employees effective. Organizations also need to support employees to reduce work-family conflict.
\end{abstract}

\section{Introduction}

World Health Organization (WHO) declared Coronavirus Disease 2019 (COVID-19) as a pandemic on March 11, 2020, because of its rapid geographical spread, across continents and around the globe (WHO, 2020). The Indonesian government has decided on strategies to curb COVID-19 cases growth, for example, encouraging people to work, study, and worship from home. Working from home can affect their psychological state and increase their psychological distress due to the demands of work faced. As Oshio, Inoue, \& Tsutsumi (2017) stated, work-family conflicts happen when individuals simultaneously face the demands of work and have to undergo various roles and obligations related to family life

Psychological distress refers to the emotional suffering experienced by individuals due to difficulties coping with stressors and demands in daily life (Islam, 2019). Research showed psychological distress had been linked to increased mortality due to various health problems such as cardiovascular problems, chronic obstructive pulmonary problems, and cancer (McLachlan \& Gale, 2018; Russ et al., 2012) and can reduce employee creativity (Kalyar, Saeed, Usta, \& Shafique, 2021). Psychological distress is caused by conflicts that arise between the role of work and family and affects spousal 
undermining, and a more significant effect on men than women (Eddleston \& Mulki, 2015). The condition causes negative feelings and thoughts, including fear, anxiety, and depression (Kyron, Rikkers, LaMontagne, Bartlett, \& Lawrence, 2019). Psychological distress results from general life situations experienced by individuals consist of two main affective components: depression and anxiety (Kessler et al., 2002). This research only focused on psychological distress in the workplace setting.

Conflicts arising from work-home interactions (WHIs) (Oshio et al., 2017) as the burden on work affects the obstruction of things that individuals have to do at home cause psychological distress, affecting both physical and psychological health (Davis, Gere, \& Sliwinski, 2017). Working from home causes interactions between an individual's work and home life (Bilodeau, Marchand, \& Demers, 2019; Darouei \& Pluut, 2021; van der Lippe \& Lippényi, 2020). An imbalance can place a burden on one of these domains, which in turn can affect another domain such that an individual may fail to meet their obligations at work and home (Oshio et al., 2017). This condition triggers work-family conflicts for employees; thus, they must manage conflicting work and home demands (Geurts et al., 2005; van der Lippe \& Lippényi, 2020).

WHIs, occur when the behavior function of a worker in one domain is influenced by reactions (either positive or negative) in other domains (e.g., the home is affected by positive or negative reactions from the office) (Geurts et al., 2005; van der Lippe \& Lippényi, 2020). Balanced work and home domains can effectively help individuals save energy, develop optimal abilities in both, and assume more responsibility for their situations (Rothmann \& Baumann, 2014). The dimensions of WHIs include negative work-home interactions (NWHIs), negative home-work interactions (NHWIs), positive work-home interactions (PWHIs), and positive home-work interactions (PHWIs) (Geurts et al., 2005). An NWHI is an unfavorable reaction that develops in the workplace that can inhibit function at home. An NHWI is a reaction to a negative burden developed at home that can inhibit function at work. An NWHIs are related to workers' mental health (Klumb, Voelkle, \& Siegler, 2017) even previous study has indicated that NWHIs and NHWIs affect depression and anxiety (Davis et al., 2017). A PWHI is a reaction to positive loads obtained at work that can help function at home. Finally, a PHWI is a reaction to positive loads obtained at home that can help workplace functions. Abubakar (2018) revealed that PHWIs and PWHIs had more significant effects on depression than NHWIs and NWHIs. High PHWIs and PHWIs have a more significant effect in reducing depression than NHWIs and NWHIs have in increasing depression.

Working from home (WFH) needs to be independent due to lack of communication with colleagues and lack of supervisor support resulting in stress that impacts both the home and work (Bilodeau et al., 2019; Nakrošienè, Bučiūnienè, \& Goštautaitè, 2019). WFH has many advantages, including allowing employees flexibility in time management and reducing commute time to and from work (Nakrošienè et al., 2019). Conversely, since there is no direct supervision from their superiors, employees who WFH may require a higher level of self-control to ensure that the work is carried out correctly (Nakrošiene et al., 2019). In addition, when they are WFH, they may also be interrupted by non-work or personal activities such as childbearing or household tasks, which can create work-home conflict (Delanoeije, Verbruggen, \& Germeys, 2019). Further, WFH needs to use technology to support their work, such as checking emails and video conferencing (Kim \& Hollensbe, 2018). Constant use of technology then may lead to cyberloafing, which is a way employees escape from their work by accessing the internet to do non-work activities during work hours (Akbulut, Dursun, Dönmez, \& 
Şahin, 2016; Lim \& Chen, 2012). All these interactions between work and home, and vice versa, and pressure from technology uses may create boredom, which leads to cyberloafing (Koay \& Soh, 2018). Even though cyberloafing is a counterproductive behavior, it can be used as a stress coping method (Baskaran, Nedunselian, Mahadi, \& Mahmood, 2019; Lim \& Chen, 2012). Cyberloafing activities can replenish their energy and regain enthusiasm for their work (Andel, Kessler, Pindek, Kleinman, \& Spector, 2019; Koay \& Soh, 2018). Therefore, cyberloafing has been found to benefit employees' emotions (Lim \& Chen, 2012; Pindek, Krajcevska, \& Spector, 2018).

This study focuses on the relationship between WHIs dimensions and psychological distress and determines whether cyberloafing mediates this relationship. Although the relationship between WHIs and work stress had been studied previously (Laba \& Geldenhuys, 2018), this study aimed to investigate its relationship with cyberloafing. The involvement of cyberloafing in the relationship between WHIs and psychological distress has not been studied yet. Investigating cyberloafing as a potential mediator in the relationship then becomes this study's main strength. The following research hypotheses were proposed:

Hypothesis 1 (H1): All dimensions of WHIs significantly predict psychological distress, such that:

H1a: NWHIs positively predict psychological distress;

H1b: NHWIs positively predict psychological distress;

H1c: PWHIs negatively predict psychological distress;

H1d: PHWIs negatively predict psychological distress.

Hypothesis $2(\mathrm{H} 2)$ : Cyberloafing mediates the relationship between all dimensions of WHI and psychological distress.

\section{Method}

\section{Research Design}

A cross-sectional study was undertaken in April 2020 in a government institution in Indonesia that had employees across the country. The researchers also sought the permission of a leader of a government institution. The study was completely voluntary, and the data was collected in an anonymized manner. All respondents were given detailed notification of consent to participate in the study, assured that their information would be kept confidential, asked for a response to the questions honestly, and told that all responses were accepted. This study granted ethical approval from the Ethics Committee of the Faculty of Psychology, University of Indonesia number 009/F.Psi.Komite Etik/PDP.04.00/2018.

\section{Participants}

Two thousand seven hundred thirty-nine employees participated in this study. Of the total sample, some participants produced incomplete responses, failed to attention check the pictures, did not understand consent, or did not give consent; thus, their data had to be discarded. Ultimately, the data of 2,349 participants were analyzed. The average age of participants was 38.245 years $(S D=38.413)$. As shown in Table 1 , the majority of the participants were male $(56,5 \%)$, between 25 and 44 years old $(61,7 \%)$, and hold a Master's level degree $(56,4 \%)$. 
Table 1

Demographic Data $(N=2,349)$

\begin{tabular}{crrr}
\hline \multicolumn{2}{c}{ Gender } & $\mathrm{n}$ & $\%$ \\
\multicolumn{1}{c}{ Male } & Female & & \\
Age & & 1327 & 56.5 \\
& $15-25$ & 1022 & 43.5 \\
$25-44$ & & \\
$45-64$ & 213 & 9.1 \\
$65+$ & 1450 & 61.7 \\
Education Level & 544 & 23.2 \\
High School & 142 & 6 \\
Bachelor & & 13.2 \\
Master & 310 & 9.9 \\
Doctorate & 233 & 56.4 \\
\hline
\end{tabular}

\section{Procedures}

An official email was sent to all the employees asking them to participate in a voluntary research study. The study used an online survey tool (SurveyMonkey.com) that allowed researchers to randomize items to avoid common method variance (Podsakoff, MacKenzie, \& Podsakoff, 2012). Harman's single-factor test found no common-method variance, resulting in $15.035 \%$ of the total variance (Podsakoff et al., 2012).

All employees worked from home during data collection and only went to the office when necessary, except for echelon three and above. Echelon 3 and above leaders worked from home with alternating schedules. They were allowed to come once a week or twice a week if a critical meeting needed to be held in person.

\section{Instruments}

The Kessler-10 scale was used to measure two dimensions of psychological distress (i.e., anxiety and depression) (Kessler et al., 2002). This survey comprised ten items that have been shown to work well for determining depression and anxiety (Merson, Newby, Shires, Millard, \& Mahoney, 2021; Uddin, Islam, \& Al Mahmud, 2018). Examples of items are: "I feel unhappy" and "I feel anxious". Cronbach's alpha for this study is .911 for psychological distress. Item discrimination index ranges from .520 to .736 .

Work-home interactions were measured by a survey that comprised 22 items (Geurts et al., 2005). This survey measured four dimensions of WHIs: NWHIs, NHWIs, PWHIs, and PHWIs. Examples of items are:" I have to work so hard that I don't have time for any of my hobbies" and "The situation at home makes me irritable, so I take my frustration out on my colleagues". Previous studies have reported Cronbach's alphas of .84 for NWHI, 75 for NHWI and PWHI, and .81 for PHWI (Geurts et al., 2005). Cronbach's alphas for this study are .859 for NWHI, .705 for NHWI, .708 for PWHI, and .757 for PHWI. Item discrimination index ranges from 473 to .677 for NWHI, from .427 to .593 for NHWI, from .410 to .509 for PWHI, from .436 to .565 for PHWI.

Cyberloafing was measured using 30 items derived from (Akbulut et al., 2016). The dimensions of cyberloafing measured were sharing, shopping, real-time updating, accessing online content, and gaming/gambling. Examples of items are: "I check my friends' posts" and "I listen to music online". In previous research, sharing had a Cronbach alpha of .926, shopping of .87, real-time updating of .938, accessing online content of 
.944, and gaming/gambling of .796 (Akbulut et al., 2016). Cronbach alpha for this study is .883 for cyberloafing. Item discrimination index ranges from .348 to .539 .

The three surveys used in this study were translated and adapted to the Bahasa version. The translation process followed the translation guidelines for use in Indonesia (Sousa \& Rojjanasrirat, 2011). The translation was carried out by two people who were proficient in Indonesian and English. Three other people then compared the results of the translation.

Participants were asked to respond on a Likert scale ranging from 1 (never) to 4 (always). A four-point scale was used to avoid the central tendency bias because individuals tend to choose answers in the middle (Douven, 2018). A four-point scale has good reliability and minimizes response selection errors that may arise when there are many alternative responses (Chang, 1994).

At the beginning and end of the online survey, we also included attention checks in the form of images that appeared. Participants were directed to remember what images were displayed at the beginning of the survey. Then, reselect the images at the end of the survey. Attention checks are increasingly popular in survey research and are recommended to ensure that participants' answers are valid and not arbitrary (Kung, Kwok, \& Brown, 2018). Attention checks also ensure that participants follow the instructions given and do not make mistakes in answering (Abbey \& Meloy, 2017; Gummer, Roßmann, \& Silber, 2018).

\section{Data Analyses}

SPSS (version 26) was used to evaluate the descriptive statistics, correlations, and reliability of measuring instruments. Amos (version 26) was used to test the goodness of fit (GFI) and the hypotheses using structural equation modeling.

\section{Results}

\section{Descriptive Statistics}

The means, correlations, and reliabilities (Cronbach's alphas), and standard deviations are shown in Table 2. The Cronbach's alpha coefficient for each variable was .705 and above. Based on the descriptive analysis, it can be concluded that all the instruments had satisfactory reliability.

Table 2

Descriptive Statistics, Reliabilities, and Correlations

\begin{tabular}{ccccccccc}
\hline & Means & SD & NWHI & NHWI & PWHI & PHWI & PD & CL \\
\hline NWHI & 2.031 & .537 & $\mathbf{. 8 5 9}$ & & & & & \\
NHWI & 1.600 & .475 & $.556^{* *}$ & $\mathbf{. 7 0 5}$ & & & & \\
PWHI & 2.921 & .503 & $-.274^{* *}$ & $-.265^{* *}$ & $\mathbf{. 7 0 8}$ & & & \\
PHWI & 3.176 & .492 & $-.202^{* *}$ & $-.272^{* *}$ & $.616^{* *}$ & .757 & & \\
PD & 1.706 & .468 & $.455^{* *}$ & $.515^{* *}$ & $-.308^{* *}$ & $-.356^{* *}$ & $\mathbf{. 9 1 1}$ & \\
TCL & 2.058 & .326 & $.105^{* *}$ & $.124^{* *}$ & $.061^{* *}$ & .009 & $.253^{* *}$ & $\mathbf{. 8 8 3}$ \\
\hline
\end{tabular}

\section{Goodness of Fit}

We use index $\chi 2$, Goodness-of-fit (GFI), the Root Mean Square Residual (RMR), the Normed-fit (NFI), and the Comparative Fit Index (CFI) to evaluate the goodness of fit of 
the model (Hooper, Coughlan, \& Mullen, 2008). The $\chi^{2} /$ degree of freedom value indicates that the model is not fit $\left(\chi^{2} /\right.$ degree of freedom $\left.=683.705, p=0.000\right)$. As the $\chi^{2}$ value is sensitive to sample size, a chi-squared test almost always rejects models with large samples (Hooper et al., 2008). A small sample will make the chi-squared statistic lack strength because it cannot distinguish between good and bad fit models, so researchers must use other alternative indices (Hooper et al., 2008; Perry, Nicholls, Clough, \& Crust, 2015). Other measures of the model's goodness of fit were tested by using GFI, NFI, CFI, and RMR. The results showed a perfect fit (Hooper et al., 2008; Perry et al., 2015).

Table 3

The Goodness of Fit Model

\begin{tabular}{lccc}
\hline \multicolumn{1}{c}{ Type of Fit Index } & Cut Off & Result & Interpretation \\
\hline$\chi^{2} /$ degree of freedom & $p>.05$ & 683.705 & Not fit \\
& & $p=.000$ & Fit \\
GFI & GFI $\geq .95$ & 1.000 & Fit \\
NFI & NFI $\geq .95$ & 1.000 & Fit \\
CFI & CFI $\geq .95$ & 1.000 & Fit \\
RMR & RMR $\leq .05$ & .000 & \\
\hline
\end{tabular}

\section{Standardized Regression Coefficients}

Table 4 shows the regression weight for the model indicating NWHIs, NHWIs, PWHIs, and PHWIs predict psychological distress. NWHIs $(\beta=.230, S E=.098, p=.000)$ and NHWIs $(\beta=.291, S E=.114, p=.000)$ had positive and significant effects on psychological distress. While PWHIs $(\beta=-.041, S E=.114, p=.000)$ and PHWIs $(\beta=-$ $.201, S E=.115, p=.000$ ) had negative and significant effects on psychological distress. Thus, H1, which consists of H1a, H1b, H1c, H1d, was accepted

Table 4

Regression Weights for Model

\begin{tabular}{|c|c|c|c|c|c|}
\hline & \multicolumn{2}{|c|}{ Estimates } & \multirow{2}{*}{ S.E } & \multirow{2}{*}{$C . R$} & \multirow{2}{*}{$p$} \\
\hline & Unstandardized & Standardized & & & \\
\hline $\mathrm{CL} \leftarrow \mathrm{NWHI}$ & .046 & .077 & .009 & 5.338 & $* * *$ \\
\hline $\mathrm{CL} \leftarrow \mathrm{NHWI}$ & .070 & .101 & .010 & 7.020 & $* * *$ \\
\hline $\mathrm{CL} \leftarrow \mathrm{PWHI}$ & .074 & .113 & .010 & 7.405 & $* * *$ \\
\hline $\mathrm{CL} \leftarrow \mathrm{PHWI}$ & -.11 & -.017 & .010 & -1.121 & .262 \\
\hline $\mathrm{PD} \leftarrow \mathrm{NWHI}$ & 1.979 & .230 & .098 & 20.099 & $* * *$ \\
\hline $\mathrm{PD} \leftarrow \mathrm{NHWI}$ & 2.908 & .291 & .114 & 25.444 & $* * *$ \\
\hline $\mathrm{PD} \leftarrow \mathrm{PWHI}$ & -.384 & -.041 & .114 & -3.358 & $* * *$ \\
\hline $\mathrm{PD} \leftarrow \mathrm{PHWI}$ & -1.925 & -.201 & .115 & -16.772 & $* * *$ \\
\hline $\mathrm{PD} \leftarrow \mathrm{CL}$ & 2.760 & .193 & .136 & 20.330 & $* * *$ \\
\hline
\end{tabular}

\section{Indirect Effect}

Table 5 shows the results related to the second hypothesis. AMOS Plug-ins were used to ascertain the indirect effects on variables. Based on the analysis, cyberloafing mediates the relationship between NWHIs $(\beta=.015,95 \% C I[.088, .174])$, NHWIs $(\beta=.019,95 \%$ $C I[.144, .250])$, and PWHIs $(\beta=.022,95 \% C I[.155, .259])$ and psychological distress (Hayes, 2018). However, cyberloafing does not mediate the relationship between PHWIs and psychological distress 
Table 5

Indirect Effects for the Relationship between All Variables

\begin{tabular}{|c|c|c|c|c|c|}
\hline & \multicolumn{2}{|c|}{ Estimate } & \multicolumn{2}{|c|}{$95 \% C I$} & \multirow[t]{2}{*}{$p$-Value } \\
\hline & Unstandardized & Standardized & Lower & Upper & \\
\hline $\mathrm{NWHI} \rightarrow \mathrm{CL} \rightarrow \mathrm{PD}$ & .128 & $.015^{* * *}$ & .088 & .174 & .001 \\
\hline $\mathrm{NHWI} \rightarrow \mathrm{CL} \rightarrow \mathrm{PD}$ & 194 & $.019 * * *$ & .144 & .250 & .001 \\
\hline $\mathrm{PWHI} \rightarrow \mathrm{CL} \rightarrow \mathrm{PD}$ & .205 & $.022 * * *$ & .155 & .259 & .001 \\
\hline $\mathrm{PHWI} \rightarrow \mathrm{CL} \rightarrow \mathrm{PD}$ & -.031 & -.003 & -.081 & .019 & .318 \\
\hline
\end{tabular}

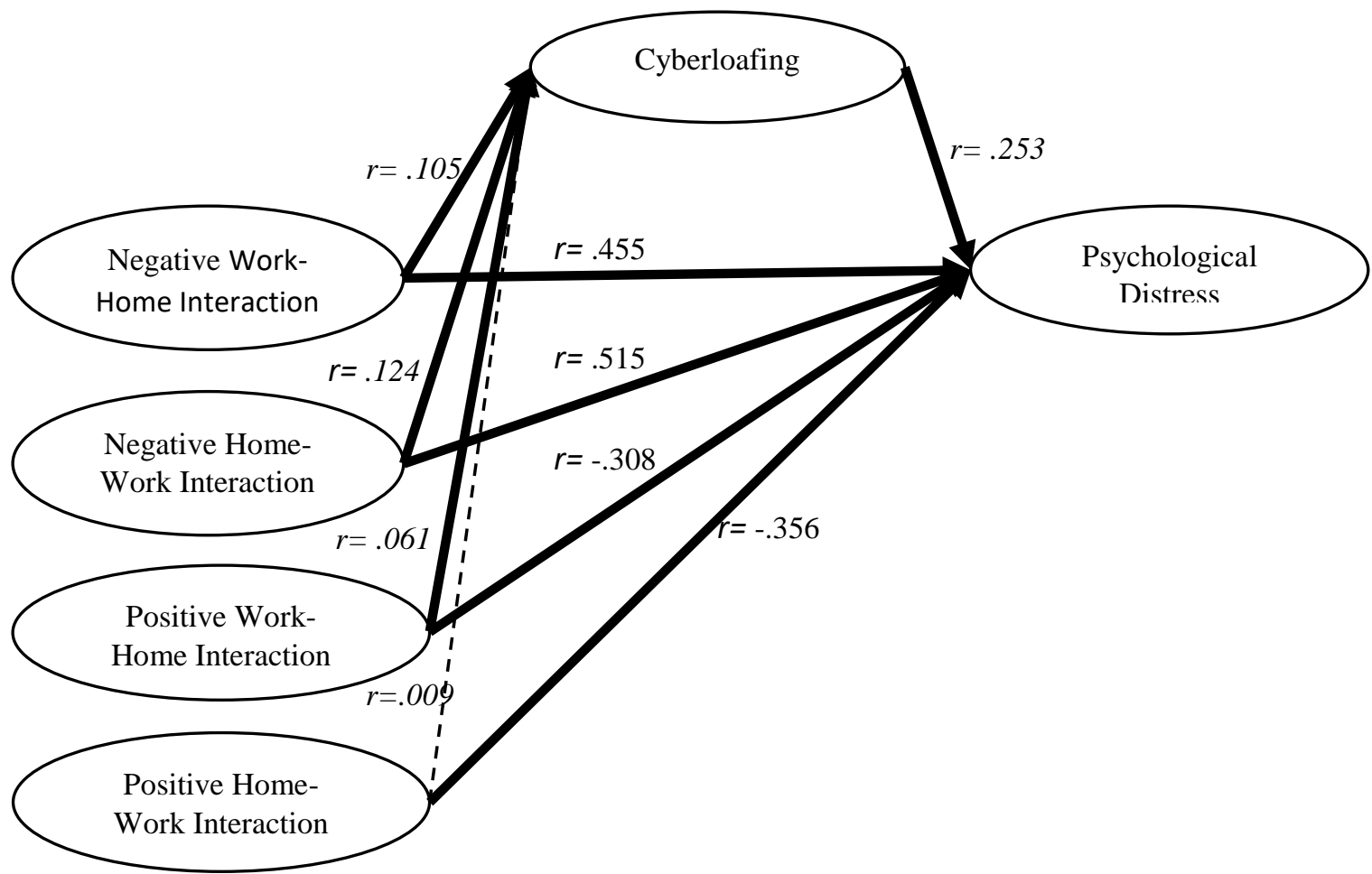

Figure 1. Structural equation model predicting psychological distress.

Note: Dotted lines indicate non-significant relations; bold lines indicate significant indirect paths. $r=$ correlation index

\section{Discussion}

Based on hypothesis testing, NWHIs, NHWIs, PWHIs, and PHWIs predicted psychological distress. Cyberloafing had a mediation role in the relationship between WHIs and psychological distress, with the direct effect greater than the indirect effect.

High levels of NWHIs and NHWIs increase psychological distress in employees. This study's results are in line with the findings of previous studies that showed that NWHIs and NHWIs affect depression and anxiety (Davis et al., 2017; Zhou, Zhang, Li, \& Chen, 2020). A negative burden at work will make household affairs more challenging to undertake and vice versa (Cerrato \& Cifre, 2018). This condition will upset the balance between work and home (Geurts et al., 2005). These findings should concern policymakers, as the interactions between home and work will last longer due to the pandemic. Under the "New Normal," only $50 \%$ of employees attend the office while the 
remainder WFH (Kementerian Dalam Negeri, 2021). Negative effects arising from office conditions place pressure on home affairs (Geurts et al., 2005; Oshio et al., 2017; Zhou et al., 2020). If home affairs are obstructed, employees' performances will also decrease, ultimately hindering organizational goals.

This study's results showed that increasing PWHIs and PHWIs decreases employees' psychological distress when employees WFH. Previous studies also found that PHWIs have a particular effect in circumstances in which employees must manage multiple works and family demands (Bowen, Govender, Edwards, \& Catell, 2018). The relationships between family life and work-life (and vice versa) affect individuals and their perceptions of their social environments and organizations (Oshio et al., 2017). Thus, companies must create a positive work atmosphere to balance and complete all their work and home affairs (Liu, Cao, Zhang, \& Wu, 2020). Companies need to ensure that the workload given can be completed properly and is more flexible while WFH with the support of sophisticated technology so that it does not have an impact on family life which in turn has an impact on psychological distress (Kim \& Hollensbe, 2018). A workplace culture that supports work-family harmony is critical for management support, employee support, and ensuring employees' commitment to organizations (Odle-Dusseau, Hammer, Crain, \& Bodner, 2016; Oshio et al., 2017). This support will make employees more excited and happier at work and improve organizational performance while WFH.

This research showed that cyberloafing mediates the relationship between all dimensions of WHIs and psychological distress, except PHWI. When employees experience NWHIs and NHWIs, they divert their attention by engaging in cyberloafing, affecting their psychological distress. When employees divert their attention by engaging in cyberloafing, employees will experience psychological distress more. Notably, previous study has assumed that employees use cyberloafing to cope with conditions from negative work experiences such as stress (Lim \& Chen, 2012). Work and home demands coincide will raise employees' level of stress when WFH, so they may engage in cyberloafing to reduce their stress level. However, as the results showed, if employees engage in cyberloafing, work and home affairs become dormant and unfinished, which increases psychological distress. Moreover, Sampat \& Basu (2017) stated that cyberloafing could reduce productivity and lose intellectual property and time. Therefore, employees must reduce cyberloafing not further increase psychological distress caused by the demands of work and home.

PWHIs can also increase employees' cyberloafing; however, it also increases employees' psychological distress. This can happen because of the lack of demands from work which causes a lot of time left for employees and can ultimately lead to boredom for employees, which leads to cyberloafing (Koay \& Soh, 2018; Wu \& Chen, 2020). Employees who feel bored and lack self-control will do cyberloafing (Koay, Soh, \& Chew, 2017; Mercado, Giordano, \& Dilchert, 2017).

This study results showed cyberloafing does not mediate the relationship between PHWIs and psychological distress. When employees feel happy and can carry out their roles well in home life, their work-life will also be good. PHWI has no impact on cyberloafing. Therefore cyberloafing does not have a role in the relationship between PHWIs and psychological distress. Research from (Speights, Bochantin, \& Cowan, 2020) found that if employees show positive emotions because they can complete obligations at home, employees will lead a more productive work life.

There are several limitations to this research. First, the data retrieval was carried out at a government organization. A leader sent a notification letter to all employees about 
the survey. Consequently, some participants may have provided ideal answers due to concerns that their supervisors would be assessing their responses. Second, the data were collected at the beginning of the total work from home policy. However, in currently new normal conditions, the policy is changed to work from home for three days and work from the office for two days. These policy changes may alter the results.

Finally, this study did not include data on the marital status of the participants. In future studies, data on participants' marital status should be gathered to examine any differences between married and single employees. Davis et al. (2017) stated that negative family-to-work spillover causes a decrease in employee marital satisfaction and affects their jobs. The difference in roles between married and unmarried employees may affect their work interactions at home, which may affect their psychological stress.

\section{Conclusion}

The COVID-19 pandemic has forced organizations to find the best solutions by utilizing technological developments to improve their organizational performance under the health protocols set by the government. Working from home is one of the best solutions in the current situation to lower the chance of the COVID-19 spreading. However, this study found work-home interaction and home-work interaction have an impact on psychological distress mediated by cyberloafing. Based on this study results, either negative or positive work-home interaction influences cyberloafing, which will increase psychological distress. Therefore, organizations can intervene to ensure employees get the proper support they need, primarily mental and technological support, to efficiently complete work.

\section{References}

Abbey, J. D., \& Meloy, M. G. (2017). Attention by design: Using attention checks to detect inattentive respondents and improve data quality. Journal of Operations Management, 53-56(1), 63-70. https://doi.org/10.1016/j.jom.2017.06.001

Abubakar, A. M. (2018). Linking work-family interference, workplace incivility, gender and psychological distress. Journal of Management Development, 37(3), 226-242. https://doi.org/10.1108/JMD-06-2017-0207

Akbulut, Y., Dursun, Ö. Ö., Dönmez, O., \& Şahin, Y. L. (2016). In search of a measure to investigate cyberloafing in educational settings. Computers in Human Behavior, 55, 616-625. https://doi.org/10.1016/j.chb/2015.11.002

Andel, S. A., Kessler, S. R., Pindek, S., Kleinman, G., \& Spector, P. E. (2019). Is cyberloafing more complex than we originally thought? Cyberloafing as a coping response to workplace aggression exposure. Computers in Human Behavior, 101, 124-130. https://doi.org/10.1016/j.chb.2019.07.013

Baskaran, S., Nedunselian, N., Mahadi, N., \& Mahmood, Z. (2019). An epidemic phenomenon of workplace cyberloafing: Investigations and implications. International Journal of Work Organisation and Emotion, 10(4), 357-371. https://doi.org/10.1504/IJWOE.2019.106894

Bilodeau, J., Marchand, A., \& Demers, A. (2019). Work, family, work-family conflict and psychological distress: A revisited look at the gendered vulnerability pathways. Stress and Health, 36(1), 75-87. https://doi.org/10.1002/smi.2916

Bowen, P., Govender, R., Edwards, P., \& Catell, K. (2018). Work-related contact, work- 
family conflict, psychological distress and sleep problems experienced by construction professionals: An integrated explanatory model. Construction $\begin{array}{llll}\text { Management } \quad \text { and } & \text { 153-174. }\end{array}$ https://doi.org/10.1080/01446193.2017.1341638

Cerrato, J., \& Cifre, E. (2018). Gender inequality in household chores and work-family conflict. Frontiers in Psychology, 9(1330). https://doi.org/10.3389/fpsyg.2018.01330

Chang, L. (1994). A psychometric evaluation of 4-Point and 6-Point Likert-type scales in relation to reliability and validity. Applied Psychological Measurement, 18(3), 205215. https://doi.org/10.1177/014662169401800302

Darouei, M., \& Pluut, H. (2021). Work from home today for a better tomorrow! How working from home influences work-family conflict and employees' start of the next workday. Stress and Health, Online First. https://doi.org/10.1002/smi.3053

Davis, K. D., Gere, J., \& Sliwinski, M. J. (2017). Investigating the work-family conflict and health link: Repetitive thought as a mechanism. Stress and Health, 33(4), 330338. https://doi.org/10.1002/smi.2711

Delanoeije, J., Verbruggen, M., \& Germeys, L. (2019). Boundary role transitions: A dayto-day approach to explain the effects of home-based telework on work-to-home conflict and home-to-work conflict. Human Relations, 72(12), 1843-1868. https://doi.org/10.1177/0018726718823071

Douven, I. (2018). A Bayesian perspective on Likert scales and central tendency. Psychonomic Bulletin and Review, 25(3), 1203-1211. https://doi.org/10.3578/s13423-017-1344-2

Eddleston, K. A, \& Mulki, J. (2015). Toward understanding remote workers' management of work-family boundaries: The complexity of workplace embeddedness. Group and Organization Management, 42(3), 346-387. https://doi.org/10.117/1059601115619548

Geurts, S. A. E., Taris, T. W., Kompier, M. A. J., Dikkers, J. S. E., VanHooff, M. L. M., \& Kinnunen, U. M. (2005). Work-home interaction from a work psychological perspective: Development and validation of a new questionnaire, the SWING. Work and Stress, 19(4), 319-339. https://doi.org/10.1080/02678370500410208

Gummer, T., Roßmann, J., \& Silber, H. (2018). Using instructed response items as attention checks in web surveys: Properties and implementation. Sociological Methods and Research, 50(1), 238-264. https://doi.org/10.1177/0049124118769083

Hayes, A. F. (2018). Introduction to mediation, moderation, and conditional process analysis : A regression - based approach. The Guilford Press.

Hooper, D., Coughlan, J., \& Mullen, M. R. (2008). Structural equation modelling: Guidelines for determining model fit. Electronic Journal of Business Research Methods, 6(1), 53-60.

Islam, F. M. A. (2019). Psychological distress and its association with socio-demographic factors in a rural district in Bangladesh: A cross-sectional study. PloS One, 14(3), e0212765. https://doi.org/10.1371/journal.pone.0212765

Kalyar, M. N., Saeed, M., Usta, A., \& Shafique, I. (2021). Workplace cyberbullying and creativity: Examining the roles of psychological distress and psychological capital. Management Research Review, 44(4), 607-624. https://doi.org/10.1108/MRR-032020-0130

Kementerian Dalam Negeri. (2021). Instruksi Menteri Dalam Negeri Nomor 3 Tahun 
2021 (Instruction of the Minister of Home Affairs Number 3 of 2021). Kementerian Dalam Negeri.

Kessler, R. C., Andrews, G., Colpe, L. J., Hiripi, E., Mroczek, D. K., Normand, S. L. T., ... Zaslavsky, A. M. (2002). Short screening scales to monitor population prevalences and trends in non-specific psychological distress. Psychological Medicine, 32(6), 959-976. https://doi.org/10.1017/S0033291702006074

Kim, S., \& Hollensbe, E. (2018). When work comes home: Technology-related pressure and home support. Human Resource Development International, 21(2), 91-106. https://doi.org/10.1080/13678868.2017.1366177

Klumb, P. L., Voelkle, M. C., \& Siegler, S. (2017). How negative social interactions at work seep into the home: A prosocial and an antisocial pathway. Journal of Organizational Behavior, 38(5), 629-649. https://doi.org/10.1002/job.2154

Koay, K. Y., \& Soh, P. C. H. (2018). Should cyberloafing be allowed in the workplace? Human Resource Management International Digest, 26(7), 4-6. https://doi.org/10.1108/HRMID-05-2018-0107

Koay, K. Y., Soh, P. C. H., \& Chew, K. W. (2017). Do employees' private demands lead to cyberloafing? The mediating role of job stress. Management Research Review, 40(9), 1025-1038. https://doi.org/10.1108/MRR-11-2016-0252

Kung, F. Y. H., Kwok, N., \& Brown, D. J. (2018). Are attention check questions a threat to scale validity? Applied Psychology, 67(2), 264-283. https://doi.org/10.1111/apps.12108

Kyron, M. J., Rikkers, W., LaMontagne, A., Bartlett, J., \& Lawrence, D. (2019). Workrelated and nonwork stressors, PTSD, and psychological distress: Prevalence and attributable burden among Australian police and emergency services employees. Psychological Trauma: Theory, Research, Practice, and Policy, Advance online publication. https://doi.org/10.1037/tra0000536

Laba, K., \& Geldenhuys, M. (2018). Positive interaction between work and home, and psychological availability on women's work engagement: A 'shortitudinal' study. SA Journal of Industrial Psychology, 44(0), a1538. https://doi.org/10.4102/sajip.v44i0.1538

Lim, V. K. G., \& Chen, D. J. Q. (2012). Cyberloafing at the workplace: Gain or drain on work? Behaviour and Information Technology, 31(4), 343-353. https://doi.org/10.1080/01449290903353054

Liu, C., Cao, J., Zhang, P., \& Wu, G. (2020). Investigating the relationship between workto-family conflict, job burnout, job outcomes, and affective commitment in the construction industry. International Journal of Environmental Research and Public Health, 17(16), 1-20. https://doi.org/10.3390/ijerph17165995

McLachlan, K. J. J., \& Gale, C. R. (2018). The effects of psychological distress and its interaction with socioeconomic position on risk of developing four chronic diseases. Journal of Psychosomatic Research, 109, 79-85. https://doi.org/10.1016/j.jpsychores.2018.04.004

Mercado, B. K., Giordano, C., \& Dilchert, S. (2017). A meta-analytic investigation of cyberloafing. Career Development International, 22(5), 546-564. https://doi.org/10.1108/CDI-08-2017-0142

Merson, F., Newby, J., Shires, A., Millard, M., \& Mahoney, A. (2021). The temporal stability of the Kessler Psychological Distress Scale. Australian Psychologist, 56(1), 38-45. https://doi.org/10.1080/00050067.2021.1893603

Nakrošienè, A., Bučiūnienè, I., \& Goštautaitè, B. (2019). Working from home: 
Characteristics and outcomes of telework. International Journal of Manpower, 40(1), 87-101. https://doi.org/10.1108/IJM-07-2017-0172

Odle-Dusseau, H. N., Hammer, L. B., Crain, T. L., \& Bodner, T. E. (2016). The influence of family-supportive supervisor training on employee job performance and attitudes: An organizational work-family intervention. Journal of Occupational Health Psychology, 21(3), 296-308. https://doi.org/10.1037/a0039961

Oshio, T, Inoue, A., \& Tsutsumi, A. (2017). Examining the mediating effect of work-tofamily conflict on the associations between job stressors and employee psychological distress: A prospective cohort study. BMJ Open, 7(8), e015608. https://doi.org/10.1136/bmjopen-2016-015608

Perry, J. L., Nicholls, A. R., Clough, P. J., \& Crust, L. (2015). Assessing model fit: Caveats and recommendations for confirmatory factor analysis and exploratory structural equation modeling. Measurement in Physical Education and Exercise Science, 19(1), 12-21. https://doi.org/10.1080/1091367X.2014.952370

Pindek, S., Krajcevska, A., \& Spector, P. E. (2018). Cyberloafing as a coping mechanism: Dealing with workplace boredom. Computers in Human Behavior, 86, 147-152. https://doi.org/10.1016/j.chb.2018.04.040

Podsakoff, P. M., MacKenzie, S. B., \& Podsakoff, N. P. (2012). Sources of method bias in social science research and recommendations on how to control it. Annual Review of Psychology, 63, 539-569. https://doi.org/10.1146/annurev-psych-120710-100452

Rothmann, S., \& Baumann, C. (2014). Employee engagement: The effects of workhome/home-work interaction and psychological conditions. South African Journal of Economic and Management Sciences, 17(4), 515-530. https://doi.org/10.4102/SAJEMS.V1714.419

Russ, T. C., Stamatakis, E., Hamer, M., Starr, J. M., Kivimäki, M., \& Batty, G. D. (2012). Association between psychological distress and mortality: Individual participant pooled analysis of 10 prospective cohort studies. BMJ, 345, e4933. https://doi.org/10.1136/bmj.e4933

Sampat, B., \& Basu, P. A. (2017). Cyberloafing: The di(sguised)gital way of loafing on the job. IUP Journal of Organizational Behavior, 16(1), 19-37.

Sousa, V. D., \& Rojjanasrirat, W. (2011). Translation, adaptation and validation of instruments or scales for use in cross-cultural health care research: A clear and userfriendly guideline. Journal of Evaluation in Clinical Practice, 17(2), 268-274. https://doi.org/10.1111.j.1365-2573.2010.01434.x

Speights, S. L., Bochantin, J. E., \& Cowan, R. L. (2020). Feeling, expressing, and managing emotions in work-family conflict. Journal of Business and Psychology, 35(3), 363-380. https://doi.org/10.1007/s10869-019-09626-x

Uddin, M. N., Islam, F. M. A., \& AlMahmud, A. (2018). Psychometric evaluation of an interview-administered version of the Kessler 10-item questionnaire (K10) for measuring psychological distress in rural Bangladesh. BMJ Open, 8(6), e022967. https://doi.org/10.1136/bmjopen-2018-022967

van der Lippe, T., \& Lippényi, Z. (2020). Beyond formal access: Organizational context, working from home, and work-family conflict of men and women in European workplaces. Indicators Research, 151(2), 383-402. https://doi.org/10.1007/s11205018-1993-1

World Health Organization. (2020). WHO Director-General's opening remarks at the media briefing on COVID-19 - 11 March 2020. Retrieved from https://www.who.int/dg/speeches/detail/who-director-general-s-opening-remarks- 
at-the-media-briefing-on-covid-19---11-march-2020

Wu, H., \& Chen, Y. (2020). The impact of work from home ( WFH ) on workload and productivity in terms of different tasks and occupations. In: Stephanidis C. et al. (Eds). In HCI International 2020 - Late Breaking Papers: Interaction, Knowledge and Social Media. HCII 2020. Lecture Notes in Computer Science, Vol 12427. https://doi.org/10.1007/978-3-030-60152-2_52

Zhou, M., Zhang, J., Li, F., \& Chen, C. (2020). Work-family conflict and depressive symptoms among Chinese employees: Cross-level interaction of organizational justice climate and family flexibility. International Journal of Environmental Research and Public Health, 17(19), 1-17. https://doi.org/10.3390/ijerph17196954 